\title{
Radionuclide imaging of bone marrow disorders
}

\author{
Ali Agool • Andor W. J. M. Glaudemans • \\ Hendrikus H. Boersma • Rudi A. J. O. Dierckx • \\ Edo Vellenga $\cdot$ Riemer H. J. A. Slart
}

Received: 14 May 2010 / Accepted: 15 June 2010 /Published online: 13 July 2010

(C) The Author(s) 2010. This article is published with open access at Springerlink.com

\begin{abstract}
Noninvasive imaging techniques have been used in the past for visualization the functional activity of the bone marrow compartment. Imaging with radiolabelled compounds may allow different bone marrow disorders to be distinguished. These imaging techniques, almost all of which use radionuclide-labelled tracers, such as ${ }^{99 \mathrm{~m}} \mathrm{Tc}-$ nanocolloid, ${ }^{99 \mathrm{~m}} \mathrm{Tc}$-sulphur colloid, ${ }^{111} \mathrm{In}$-chloride, and radiolabelled white blood cells, have been used in nuclear medicine for several decades. With these techniques three separate compartments can be recognized including the reticuloendothelial system, the erythroid compartment and the myeloid compartment. Recent developments in research and the clinical use of PET tracers have made possible the analysis of additional properties such as cellular metabolism and proliferative activity, using ${ }^{18}$ F-FDG and ${ }^{18}$ F-FLT. These tracers may lead to better quantification and targeting of different cell systems in the bone marrow. In this review the imaging of different bone marrow targets with radio-
\end{abstract}

\footnotetext{
A. Agool

Department of Nuclear Medicine, Medical Center Twente,

Hengelo, the Netherlands
}

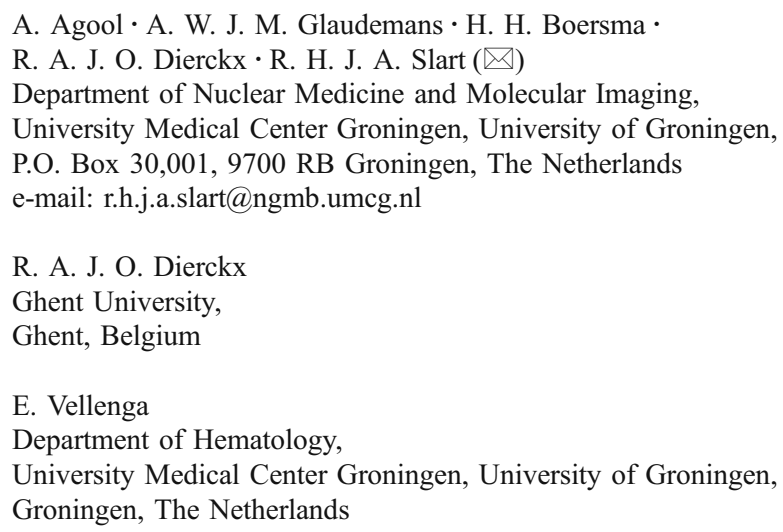

nuclides including PET tracers in various bone marrow diseases are discussed.

Keywords Bone marrow imaging $\cdot$ Bone marrow disorders

\section{Introduction}

Bone marrow is a dynamic tissue compartment in the cavity of bones. In adults, haematopoietic cells are produced by the bone marrow cells in the large bones that account for $2-$ $5 \%$ of an adult's weight [1]. In the past, a distinction was made between red marrow which consists of haematopoietic cells and yellow marrow which consists of adipocytes. It is now general accepted that a small fraction of cells, the so-called haematopoietic stem cells (HSCs) reside in specific areas of the bone marrow including the osteoblastic and vascular niche [1]. These HSC have the potential for self-renewal but also for proliferation and differentiation into different cell lineages including the myeloid, erythroid and megakaryocytic lineages [2]. This process is strongly dependent on the surrounding cells of the microenvironment including mesenchymal stem cells that have the capacity to differentiate into osteoblasts, chondrocytes, adipocytes, myocytes and endothelial cells [1]. During life distinct changes occur in the composition of the bone marrow cavity. At birth, the whole bone marrow cavity contains haematopoietic cells which are gradually replaced by adipose tissue during life. In particular, the distal parts of the skeleton become depleted of haematopoietic cells with ageing.

The architecture of the haematopoietic system can be distorted strongly by a number of disorders, including malignancy. Transformation of a haematopoietic stem cell can result in expansion of the malignant clone and 
disruption of the normal haematopoietic system [3]. In acute leukaemia the bone marrow contains a population of immature cells that has lost the potential to differentiate. In myeloproliferative diseases (MPD), however, there is an expansion of a certain haematopoietic lineage that has the persisting potential for differentiation [4]. Exposure of haematological malignancies and solid tumours to radiation or chemotherapy will eliminate many of the rapidly dividing cells of the bone marrow. The degree and extent of this process will determine the severity of the bone marrow aplasia and duration of peripheral pancytopenia. Limited diagnostic procedures are available to determine the extent of bone marrow involvement. It is assumed that the material obtained with a bone marrow aspiration and biopsy from the sternum or the crista iliaca reflects the total bone marrow compartment. Using these methods, its composition and cellular components can be analysed. In addition, in vitro assays can be used to measure the potential of more primitive progenitors or stem cells [5]. However, bone marrow biopsy has distinct limitations: it is an invasive procedure and only a small proportion of the total bone marrow content is investigated. The latter may cause sampling errors. A noninvasive technique for the evaluation of the total bone marrow activity in haematological diseases, as well as for the evaluation of haematological effects of solid tumours, would therefore be invaluable.

In this review we describe the clinical indications of bone marrow imaging as well as the most common bone marrow disorders, including bone marrow transplantation. This is combined with a review of the literature on nuclear medicine techniques that are used in diagnostic protocols for determination of bone marrow disorders. We pay special attention to recent developments in positron emission tomography (PET) techniques for the imaging of the bone marrow.

\section{Clinical indications}

Current indications for radionuclide bone marrow imaging are as follows:

1. Evaluation of patients with a discrepancy between bone marrow histology and clinical status

2. Evaluation of the degree of radiotherapy effect on bone marrow

3. Detection of extramedullary haematopoiesis (EMH)

4. Location of the optimal site for bone marrow biopsy

5. Diagnosing and staging of haematological bone marrow disorders

6. Detection of bone marrow metastases

7. Diagnosis of bone marrow infarctions

\section{Evaluation of bone marrow transplantation}

Bone marrow aspiration and biopsy are usually the standard techniques for evaluation of bone marrow function. However, sometimes a discrepancy can be found between histology of the bone marrow and the patient's laboratory and clinical findings. This may be due to a bone marrow sampling error. Noninvasive imaging using a specific bone marrow tracer can be helpful to confirm a suspected sampling error and will visualize a specific part of bone marrow functionality.

Many patients suffering from malignancies are treated with chemotherapy and/ or radiotherapy. These therapy modalities commonly cause adverse events on bone marrow activity. Bone marrow imaging may determine the amount of remaining functional bone marrow tissue and shows its biodistribution.

EMH refers to haematopoiesis taking place outside the bone marrow. This is a symptom of several haematological disorders, including chronic haemolytic anaemia (HA) and MPD. EMH occurs mainly in the liver and spleen, where it contributes to organ enlargement. It may, however, also occur in other organs or structures [6]. Clinical arguments supporting evaluation of EMH are (1) to determine the extent of EMH in the liver or spleen, (2) to determine the presence and evaluate the contribution of splenic erythropoiesis in patients under consideration for splenectomy, and (3) to evaluate mass lesions outside the liver and spleen to differentiate $\mathrm{EMH}$ from other processes. Bone marrow imaging is a diagnostic tool for determination and staging of several haematological bone marrow disorders. The latter is further addressed in the next paragraph Bone marrow disorders.

Detection of bone marrow activity as well as bone metastases is another indication for bone marrow imaging. Solid tumours have the propensity to metastasize to bone and may therefore influence the bone marrow compartment. Appropriate radiopharmaceuticals and clinical results are discussed in section Imaging the bone marrow using radionuclides.

Bone marrow infarctions are common in patients with sickle cell anaemia and its variants $\mathrm{SC}$ and $\mathrm{S}$ thalassaemia. Thalassaemia is an inherited autosomal recessive blood disease. Patients with haemoglobin SC disease inherit a gene for haemoglobin $\mathrm{S}$ from one parent, and a gene for haemoglobin $\mathrm{C}$ from the other. In fact, more than half of all patients suffering from these pathologies will experience bone marrow infarctions at some point during the course of their disease [7]. Plain X-ray images are usually normal in acute bone marrow infarction; therefore radionuclide imaging can play an additional role in the detection of acute bone marrow infarctions [8]. Finally, bone marrow imaging techniques may be useful for studying the 
proliferative activity of the haematopoietic compartment following intensive chemotherapy with and without stem cell support. Especially in the setting of autologous stem cell transplantation, determination of the remaining haematopoietic activity and its susceptibility to chemotherapeutic intervention in the case of relapse may be valuable. Bone marrow imaging may also be indicated to differentiate sepsis from bone marrow, after unclear skeletal and leucocyte scintigraphy findings; however, this is beyond the scope of this review.

\section{Bone marrow disorders}

\section{Myeloproliferative diseases}

MPDs are clonal haematopoietic stem cell disorders characterized by proliferation in the bone marrow of one or more cell lines resulting in an excessive production of cells belonging to the granulocytic, erythroid and megakaryocytic lineage (Table 1). Nowadays, a WHO classification is used for distinguishing the separate disorders [9].

Different molecular markers have been defined such as JAK2 and TET2 mutations that might further be helpful in categorizing the disorders [10]. Most frequently diagnosed are chronic myeloid leukaemia (CML), polycythaemia vera (PV), chronic idiopathic myelofibrosis (MF), and essential thrombocythaemia [11]. These disorders are characterized by the fact that enhanced proliferation of different cell lines is accompanied by a relatively normal maturation, resulting in increased number of granulocytes, red blood cells and/or platelets in the peripheral blood. MPDs mainly occur in adults with a higher prevalence in the fifth to seventh decades of life. The MPDs can have a stepwise progression that leads to bone marrow failure due to MF or ineffective haematopoiesis. Furthermore, transformation to acute leukaemia may occur.

Frequently, there is a coincidence of symptoms for the specific MPD entities. Leucocytosis, thrombocytosis, excessive megakaryocytic proliferation, MF and organome- galy are features that can occur in almost any of the MPDs. For example, both PV (malignant red blood cell proliferation) and MF (proliferation of mainly megakaryocytic elements, associated with deposition of bone marrow connective tissue) can also be associated with increased white blood cells (WBC). PV is usually associated with a mild increase in WBC counts. PV is associated with regular WBC differentiation, whereas MF is frequently associated with a mild increase in immature WBC. Leucocytosis in PV is associated with an increased risk of thrombosis. However, the primary treatment is directed towards the control of increased red blood cells [12]. Today there remains a distinct subgroup of elderly patients with PV for whom ${ }^{32} \mathrm{P}$ is the optimal treatment option, as described in the guidelines of the EANM [13]. MF is associated with variable abnormalities in $\mathrm{WBC}$, either increased with circulating immature precursors, or decreased in the presence of massive splenomegaly. The number of WBC in MF is therefore important for treatment decisions. Recently, a prognostic score index has been defined that may be helpful for establishing the proper treatment [14]. For example in PV, a survival time longer than 10 years is not uncommon [11]. The recent development of therapy targeting specific molecular defects in MPDs is an exiting field of interest in which nuclear medicine may play a key role.

\section{Myelodysplastic syndromes}

Myelodysplastic syndromes (MDS) are clonal haematopoietic stem cell diseases characterized by dysplasia and ineffective haematopoiesis in one or more of the major cell lines (Table 1). The clinical behaviour of MDS can be highly variable and separation into subgroups is based on the bone marrow cytology and cytogenetic findings according to the WHO classification [9, 15]. Subgroups that can be distinguished are refractory anaemia (with or without ringed sideroblasts), refractory cytopenia with multilineage dysplasia, refractory anaemia with excess blasts, and MDS (unclassified or with a chromosome

Table 1 Features of myeloid disorders at diagnosis

\begin{tabular}{|c|c|c|c|c|c|c|c|}
\hline Disease & BM cellularity & Blasts & Maturation & Morphology & Haematopoiesis & Blood counts & Organomegaly \\
\hline $\begin{array}{l}\text { Myelodysplastic } \\
\text { syndromes }\end{array}$ & $\begin{array}{l}\text { Usually increased, } \\
\text { occasionally } \\
\text { decreased }\end{array}$ & $\begin{array}{l}\text { Normal or } \\
\text { increased } \\
(<20 \%)\end{array}$ & Present & Dysplasia & Ineffective & Cytopenia & Uncommon \\
\hline $\begin{array}{l}\text { Myeloproliferative } \\
\text { disorders }\end{array}$ & Usually increased & $\begin{array}{l}\text { Normal or } \\
\text { slightly } \\
\text { increased } \\
(<10 \%)\end{array}$ & Present & $\begin{array}{l}\text { Relatively } \\
\text { normal }\end{array}$ & Effective & $\begin{array}{l}\text { One or more } \\
\text { myeloid cell lines } \\
\text { increased }\end{array}$ & Common \\
\hline $\begin{array}{l}\text { Acute myeloid } \\
\text { leukaemia }\end{array}$ & $\begin{array}{l}\text { Usually increased, } \\
\text { occasionally } \\
\text { decreased }\end{array}$ & $\begin{array}{c}\text { Increased } \\
(>20 \%)\end{array}$ & $\begin{array}{l}\text { Varies, } \\
\text { frequently } \\
\text { minimal }\end{array}$ & $\begin{array}{c}\text { Sometimes } \\
\text { dysplasia }\end{array}$ & $\begin{array}{l}\text { Ineffective or } \\
\text { effective }\end{array}$ & Variable & Uncommon \\
\hline
\end{tabular}


abnormality). MDS occurs predominantly in older adults with a median age of 70 years. Secondary MDS, a result of chemotherapy and/or radiotherapy for other malignant disorders, is an increasing problem and may represent as many as $15 \%$ of all patients diagnosed with MDS [16]. Secondary MDS tends to be much more severe than primary MDS. Clinical symptoms are related to cytopenia (s), most frequently anaemia, and less commonly neutropenia and/or thrombocytopenia. Organomegaly is infrequently observed. MDS prognosis depends on its morphological subtype and cytogenetic characteristics by which patients can be subdivided in low- and high-risk group. Patients in the low-risk group are treated with transfusion, haematopoietic growth factors, immunosuppressive therapy or lenolidamide. Those in the high-risk group are treated in general with therapy regimens commonly used for patients with acute leukaemia including allogeneic stem cell transplantation [15].

\section{Aplastic anaemia}

Aplastic anaemia (AA) is a rare haematological disorder caused by immune-mediated destruction of HSC in the bone marrow [17]. Haematopoiesis fails: blood cell counts are extremely low (pancytopenia) and the bone marrow appears empty. Massive AA is a life-threatening bone marrow disorder, which is associated - if untreated - with a high mortality rate [18]. In almost half of patients the AA occurs during the first three decades of life. Often, the aetiology remains unclear. AA is associated with exposure to toxins such as benzene, or with the use of certain drugs, such as chloramphenicol, carbamazepine, phenytoin, and quinine. AA is present in up to $2 \%$ of patients with acute viral hepatitis. Clinical symptoms are related to the cytopenia(s). Anaemia leads to malaise, pallor and related symptoms such as palpitations, thrombocytopenia which is associated with an increased risk of haemorrhage, bruising and petechia, and granulocytopenia which is associated with an increased risk of infection. AA can be effectively treated by immunosuppressive therapy or allogeneic stem cell transplantation. When initial treatment is started promptly, the 5-year survival rate is up to $75 \%$. After a well-matched bone marrow transplantation, patients have a long-term survival rate of up to $90 \%$ [19].

\section{Haemolytic anaemia}

Haemolytic anaemia (HA) is anaemia due to the abnormal breakdown of red blood cells either in the blood vessels (intravascular haemolysis) or extravascularly by an overactive enlarged spleen that traps circulating red blood cells and destroys them. HA can be either acquired or inherited. Acquired HA can be either immune or non-immune mediated. HA represents approximately $5 \%$ of all anaemias. Signs of anaemia (fatigue, palpitations and later heart failure) are generally present. Jaundice (as a result of bilirubin accumulation which is caused by haemoglobin degradation) can be the first sign. The overall incidence of death is low among patients with HA. However, older patients and patients with cardiovascular impairment are at higher risk compared to the rest of the population. Symptomatic treatment can be given by blood transfusion. In immune-mediated HA steroid therapy is highly effective. Splenectomy can be helpful in extravascular haemolysis, because in this case most red blood cells are removed by the spleen.

\section{Imaging the bone marrow using radionuclides}

Based on the target cell system, bone marrow imaging using radionuclides may be divided into three categories: (1) imaging the reticuloendothelial system (RES), (2) imaging erythroid precursor cells, and (3) imaging the myeloid compartment in the bone marrow. These imaging techniques, almost all using radionuclides for gamma cameras, have been used in nuclear medicine for many years. Recent developments in research and application of PET tracers has led to targeting two other pathways for imaging the bone marrow: (4) the metabolic activity, and (5) the proliferative activity. In general, PET tracers will provide absolute quantification options and a better resolution than gamma camera tracers. So the use of PET tracers may be an advantage compared to the use of gamma camera techniques for the evaluation of bone marrow disorders. The five target cell systems and the tracers for imaging the bone marrow are discussed below.

Imaging the reticuloendothelial system

The RES is part of the immune system and consists of phagocytic cells located in reticular connective tissue, primarily monocytes and macrophages. Major components of this system are the hepatic Kupffer cells, the phagocytic cells in the spleen and the phagocytic reticulum cells in the bone marrow. The RES can be easily imaged using radiolabelled colloids. Colloids are small particles that remain suspended in an appropriate medium. After intravenous injection, they are phagocytosed by macrophages and distributed throughout the body in the RES. This property is used for RES-targeted bone marrow scintigraphy.

The two most widely used tracers for scintigraphy of the RES are ${ }^{99 \mathrm{~m}} \mathrm{Tc}$-sulphur colloid and ${ }^{99 \mathrm{~m}} \mathrm{Tc}$-nanocolloid (Table 2). ${ }^{99 \mathrm{~m}} \mathrm{Tc}$-sulphur colloid is widely used in the US. The sizes of the particles range from 100 to $1,000 \mathrm{~nm}$. After intravenous administration, $5 \%$ of the injected activity 
accumulates in the RES of the bone marrow, about $90 \%$ in the liver and 5\% in the spleen [20]. Because of the high liver uptake it is difficult to evaluate the bone marrow in the lower thoracic and upper lumbar spine. ${ }^{99 \mathrm{~m}} \mathrm{Tc}$-nanocolloid is produced from microaggregated human serum albumin. More than $95 \%$ of the particles are less than $80 \mathrm{~nm}$ in size. After intravenous injection, ${ }^{99 \mathrm{~m}} \mathrm{Tc}$-nanocolloid is rapidly cleared from plasma and taken up by the RES. About 15$20 \%$ is accumulated in the bone marrow by macrophages, the rest being distributed to the liver $(70 \%)$ and spleen $(10 \%)$ [21]. Because of their small size, the uptake of nanocolloids by the marrow is greater than that of larger colloids. There is a small-sized fraction of the nanocolloid which is not taken up by the RES and is probably slowly excreted by the kidneys, thereby giving rise to a considerable blood background and urinary tract activity.

Normal bone marrow scintigraphy shows homogeneous activity in the bone marrow of the axial skeleton with uptake in the humeri and femora limited to the proximal one-third. The skull, sternum and ribs may show variable degrees of uptake. The scans are evaluated for homogeneity and intensity of uptake in normally haematopoietic marrowcontaining structures, the presence and extent of peripheral marrow expansion, central marrow depletion and focal marrow defects. Bone marrow infarctions due to sickle cell anaemia can be imaged with ${ }^{99 \mathrm{~m}} \mathrm{Tc}$-sulphur colloid, since RES activity is lacking in infarcted bone marrow, leading to the appearance of demarcated defects in bone marrow [22]. In the past, bone marrow images were often obtained using nanocolloids. This method is not now used because of its unfavourable target to background ratio [23].

\section{Imaging the erythroid bone marrow ('the red cells')}

The erythropoietic part of the bone marrow can be imaged with the PET tracer ${ }^{52} \mathrm{Fe}$. Iron is incorporated into the haemoglobin of erythrocytes.

${ }^{52} \mathrm{Fe}$ is a cyclotron-produced positron-emitting isotope with a half-life of $8.2 \mathrm{~h}$ and decays by positron emission $(57 \%)$ and by electron capture $(43 \%)$ to the radioactive daughter ${ }^{52 \mathrm{~m}} \mathrm{Mn}$ (Table 2). Another iron radioisotope, ${ }^{59} \mathrm{Fe}$, emits $\beta$-rays with the high energy of $1.59 \mathrm{MeV}$ and gamma rays of 1.1 and $1.3 \mathrm{MeV}$. It has a half-life of 45 days, and therefore imaging is of low quality with a high radiation dose. Bone marrow expansion has been demonstrated in patients with chronic HA (not acute HA), MF and, on rare occasions, PV [24]. However, the disadvantages mentioned above and the limited availability of the isotope and PET facilities have precluded its widespread use.

The tracer ${ }^{111}$ In-chloride $\left({ }^{111} \mathrm{In}_{-}-\mathrm{Cl}_{3}\right)$ distributes in the skeletal system in a manner partly similar to the distribution of iron isotopes and partly similar to that of nanocolloids [25]. ${ }^{111} \mathrm{In}-\mathrm{Cl}_{3}$ binds to transferrin in exactly the same manner as iron. The biological behaviours of indium and iron are different, because $\mathrm{In}^{3+}$ is not reduced, as is iron, to the $\mathrm{In}^{2+}$ state, but in many respects they are similar, and marrow ${ }^{111} \mathrm{In}-\mathrm{Cl}_{3}$ uptake probably reflects the distribution

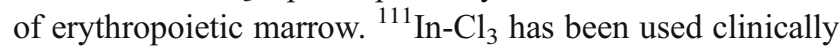
for bone marrow studies [26, 27]. It is a cyclotron-produced isotope with a half-life of 2.8 days emitting gamma rays with energies of $171 \mathrm{keV}(89 \%)$ and $245 \mathrm{keV}(94 \%)$. It decays by electron capture to stable ${ }^{111} \mathrm{Cd}$. After intravenous injection, ${ }^{111} \mathrm{In}-\mathrm{Cl}_{3}$ is rapidly coupled to serum transferrin and eliminated from the plasma with a half-life of $5 \mathrm{~h}$. About $30 \%$ of the administered tracer is found in the bone marrow, $20 \%$ in the liver, $7 \%$ in the kidneys, and $1 \%$ in the spleen. The remaining activity is distributed throughout the body fluids without any specific tissue accumulation. ${ }^{111} \mathrm{In}-\mathrm{Cl}_{3}$ is incorporated into erythrocytes only to a minor degree ( $4 \%$ of injected dose) [21]. In patients with normal bone marrow function and iron storage, the distribution of ${ }^{111} \mathrm{In}-\mathrm{Cl}_{3}$ is similar to that of the ${ }^{99 \mathrm{~m}}$ Tc-labelled colloids (Fig. 1) [25].

Patients with MF show an extension of ${ }^{111} \mathrm{In}_{-} \mathrm{Cl}_{3}$ uptake beyond the central skeleton towards the knees and sometimes ankles and elbows, together with uptake in the spleen. The clinical severity of the disease may be predicted by uptake of indium, particularly the disappearance of a physiologically active bone marrow (Fig. 1) [28]. ${ }^{111} \mathrm{In}_{-} \mathrm{Cl}_{3}$ scintigraphy of the bone marrow has been reported in patients with AA before therapeutic intervention. In almost all patients a marked reduction in the uptake was seen. Failure of ${ }^{111} \mathrm{In}-\mathrm{Cl}_{3}$ uptake correlated with a poor prognosis in patients with AA [29]. Another study was performed in patients with AA in remission for more than 2 years. Bone marrow scintigrams using ${ }^{111} \mathrm{In}_{-} \mathrm{Cl}_{3}$ showed patchy haematopoiesis which appeared to characterize the residual marrow damage in AA remission [30].

Overall, the results are not very encouraging. Moreover, bone marrow irradiated with 5 Gy failed as expected to accumulate iron but had unimpaired ${ }^{111} \mathrm{In}-\mathrm{Cl}_{3}$ uptake. Together with its nearly negligible incorporation into erythrocytes and the relatively high radiation exposure of the erythroid compartment, this almost completely precludes the use of ${ }^{111} \mathrm{In}-\mathrm{Cl}_{3}$ as a reliable agent for the assessment of erythropoietic bone marrow activity.

Imaging the myeloid bone marrow compartment ('the white cells')

${ }^{99 \mathrm{~m}}$ Tc-HMPAO or ${ }^{111}$ In-oxinate-labelled WBC are useful bone marrow imaging tracers (Table 2). Granulocytes may become damaged during the labelling process and will be trapped in the marrow, so the images obtained presumably represent the distribution of marrow reticuloendothelial cells. Although there is considerable liver activity with this 
Table 2 Overview of different radiopharmaceuticals for imaging the bone marrow

\begin{tabular}{|c|c|c|c|c|c|}
\hline Radiopharmaceutical & $\begin{array}{l}\text { Physical half } \\
\text { life }\end{array}$ & $\begin{array}{l}\text { Effective dose to bone marrow per } \mathrm{MBq} \\
(\mathrm{mSv})\end{array}$ & Cyclotron & $\begin{array}{l}\text { Quantification } \\
\text { (absolute) }\end{array}$ & Target \\
\hline \multicolumn{6}{|l|}{ Gamma camera } \\
\hline${ }^{99 \mathrm{~m}}$ Tc-sulphur colloid & $6 \mathrm{~h}$ & 0.0019 & - & - & RES \\
\hline${ }^{99 m}$ Tc-nanocolloid & $6 \mathrm{~h}$ & 0.0094 & - & - & RES \\
\hline${ }^{111}$ In-chloride & 2.3 days & 0.21 & - & - & Erythropoietic \\
\hline${ }^{99 \mathrm{~m}} \mathrm{Tc}-\mathrm{WBC}$ & $6 \mathrm{~h}$ & 0.023 & - & - & RES \\
\hline${ }^{111}$ In-WBC & 2.3 days & 0.36 & - & - & RES \\
\hline${ }^{99 \mathrm{~m}} \mathrm{Tc}-\mathrm{AGAb}$ & $6 \mathrm{~h}$ & 0.0055 & - & - & Granulopoietic \\
\hline \multicolumn{6}{|l|}{ PET } \\
\hline${ }^{52} \mathrm{Fe}$ & 8.2 days & 6.1 & $+/-$ & + & Erythropoietic \\
\hline${ }^{18} \mathrm{~F}-\mathrm{FDG}$ & $2 \mathrm{~h}$ & 0.011 & $+/-$ & + & Metabolic activity (glucose) \\
\hline${ }^{18} \mathrm{~F}-\mathrm{FLT}$ & $2 \mathrm{~h}$ & 0.029 & $+/-$ & + & Proliferative activity (DNA) \\
\hline${ }^{11} \mathrm{C}$-methionine & $20 \min$ & 0.00045 & + & + & Metabolic activity (amino acid) \\
\hline${ }^{11} \mathrm{C}$-acetate & $20 \min$ & 0.0057 & + & + & Metabolic activity (fatty acid) \\
\hline${ }^{11} \mathrm{C}$-choline & $20 \mathrm{~min}$ & 0.0019 & + & + & Cell proliferation \\
\hline${ }^{18} \mathrm{~F}$-choline & $2 \mathrm{~h}$ & 0.012 & $+/-$ & + & \\
\hline
\end{tabular}

$A G A b$ antigranulocyte antibodies, $W B C$ white blood cells, $+/-{ }^{18} \mathrm{~F}$ cyclotron-produced, but transportable for local labelling procedures.

technique, it is significantly less than seen with the colloid agents, so the spine is usually minimally obscured. However, the labour-intensive cell labelling procedure and risk of contamination makes this technique only suitable for well-equipped laboratories with qualified personnel. Label- ling of WBC may be improved using new developed kits that are safe and easy to use, with a high labelling efficiency without affecting cell vitality and function and with less risk of contamination. An alternative technique to label WBC in vivo is based on the use of murine
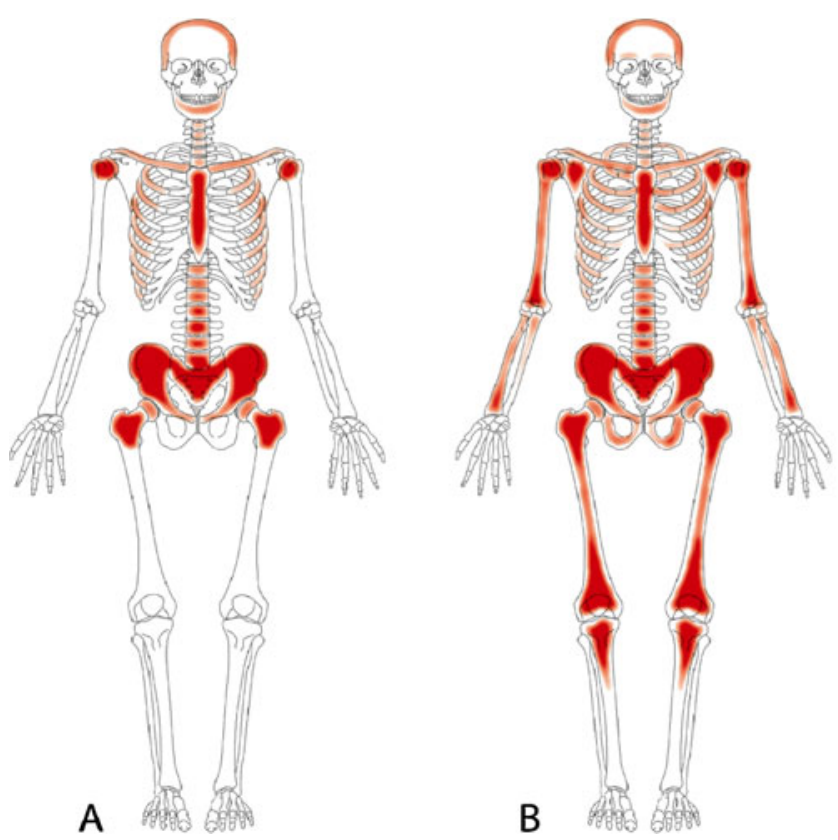

Fig. 1 Different patterns of haematopoietic bone marrow imaging. a Normal pattern of haematopoietic bone marrow activity in the central skeleton and skull. b Expansion of haematopoietic bone marrow activity more distally in the extremities. c Reduced haematopoietic

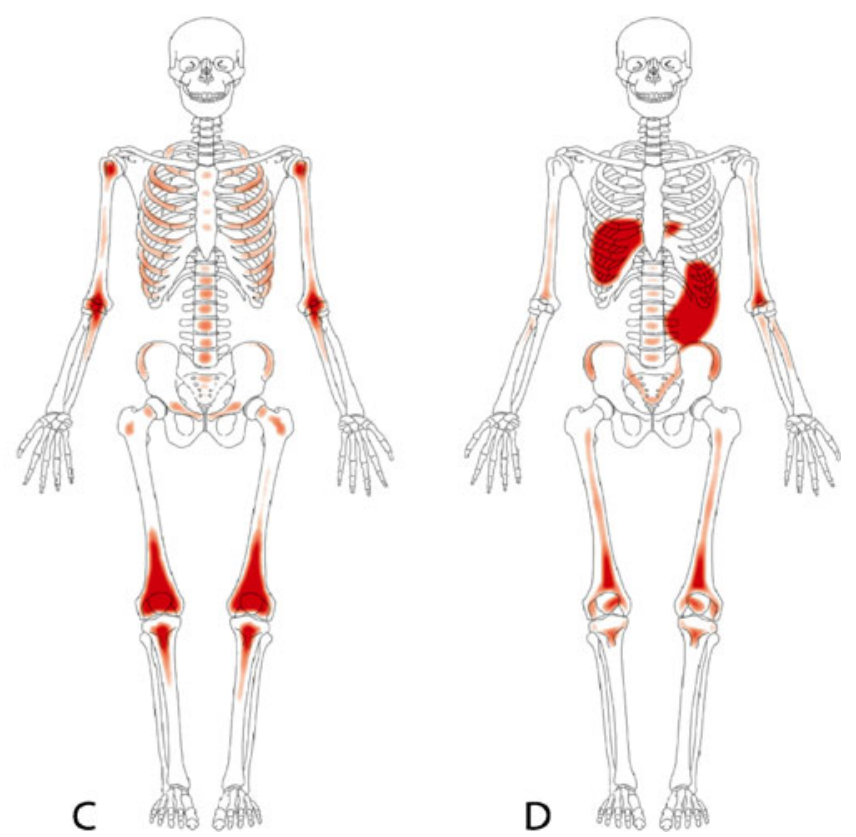

bone marrow activity in the central compartment of the skeleton and skull, as seen in AA. d MF with extramedullary erythropoiesis in the spleen and liver and reduced haematopoietic bone marrow activity in the central compartment of the skeleton and skull 
monoclonal antigranulocyte antibodies (AGAb), or $\mathrm{Fab}^{\prime}$ fragments, labelled with ${ }^{99 \mathrm{~m}} \mathrm{Tc}$. ${ }^{99 \mathrm{~m}} \mathrm{Tc}$-labelled murine monoclonal antibodies have been developed to target granulocytes in vivo. Immunoscintigraphy using ${ }^{99 \mathrm{~m}} \mathrm{Tc}$ labelled AGAb $\left({ }^{99 \mathrm{~m}} \mathrm{Tc}-\mathrm{AGAb}\right)$ directed against the nonspecific cross-reacting antigen 95 (NCA-95) has been found to be a suitable modality for bone marrow imaging because of the simplicity of its use and a high target-to-background ratio [31]. NCA-95 is expressed at the cell membrane of circulating granulocytes in blood as well as in mature myeloid cells in the bone marrow [32]. The binding of $A G A b$ to cells in the bone marrow is very rapid and extensive because of the high concentration of granulocytes, promyelocytes and myelocytes that all express the NCA-95 antigen [33]. Myeloid cells in the bone marrow are in a 50-100:1 excess compared with granulocytes in the peripheral blood. ${ }^{99 \mathrm{~m}} \mathrm{Tc}-\mathrm{AGAb}$ has been found to distribute primarily to the bone marrow after intravenous injection [34], and a progressive increase in activity in the spleen and the bone marrow is visible [33]. The uptake in the spleen can potentially be used for assessment of EMH [21].

The bone marrow status can be evaluated in three different ways: (1) estimation of the bone marrow distribution pattern, (2) identification of focal lesions (cold and hot), and (3) calculation of the uptake ratio between the sacroiliac region (corrected for background activity) and the background [35].

The bone marrow appearance in each haematological disease on ${ }^{99 \mathrm{~m}} \mathrm{Tc}-\mathrm{AGAb}$ scans seems to be characteristic. In $\mathrm{PV}$, a moderately increased uptake in the spleen is seen, probably related to EMH [36]. In MDS, generalized, small focal defects in uptake in the bone marrow are seen without indications of EMH or peripheral expansion [21]. In patients with MF, diffusely decreased bone marrow activity and prominent splenic uptake are seen. In AA, highly reduced and patchy marrow uptake is seen, but also a diffusely decreased uptake.

\section{Imaging the metabolic activity}

The well known PET tracer ${ }^{18} \mathrm{~F}$-fluorodeoxyglucose (FDG) is widely used in the evaluation of oncological and infectious diseases. FDG uptake is a measure of cell glucose utilization (glycolysis). FDG is metabolically trapped in the cell after phosphorylation as FDG-6phosphate. Unlike glucose, FDG does not further participate in the glycolytic pathway and remains in the cell. FDG uptake reflects the metabolic activity of the cell and it is useful to examine the function of the red marrow and to detect bone marrow involvement in both benign and malignant disorders. PET/CT additionally provides the synergistic advantages of precise anatomical localization of radiotracer uptake, high contrast and spatial resolution, and accurate quantification of metabolic activity at sites of radiotracer uptake.

Under normal conditions the liver, spleen, and bone marrow show homogeneous low uptake of FDG, with the bone marrow and spleen appearing less intense than the liver. Uptake of FDG in haematopoietic marrow, and its pattern and amount, can vary with age and with the level of marrow function at the time of PET examination [23]. Higher FDG uptake in the bone marrow than in the liver may indicate bone marrow activation [37]. The diffuse increase in FDG uptake in the bone marrow may be caused by the presence of malignancy or haematopoietic disease, but also may be due to an inflammatory reaction, stimulation by some types of malignancy, as a result of recent chemotheraphy, or to the administration of haematopoietic growth factors. To determine the effect of granulocyte colonystimulating factor (G-CSF) and granulocyte-macrophage colony-stimulating factor (GM-CSF) on bone marrow glucose metabolism, the specific uptake of FDG in bone marrow has been evaluated. It was shown that a substantial increase in bone marrow FDG uptake is rapidly induced by CSF treatments and should not be misinterpreted as diffuse bone metastases or bone marrow disease [38]. Therefore, FDG uptake is a sensitive marker of stimulated haematopoiesis, and both the extension and the intensification of uptake should be taken into account during haematopoietic growth factor therapy [39]. FDG uptake in the bone marrow compartment can be quantified using the standardized uptake value.

Patients with PV show a diffuse elevated FDG uptake in the bone marrow, as a result of bone marrow stimulation related to the clonal expansion of multipotent haematopoietic progenitor cells in this disease. When diffuse high marrow uptake of FDG is seen, PV should be considered in the differential diagnosis in the absence of an another aetiology $[40,41]$. In a case report, a patient with MF was reported to show a markedly increased FDG uptake throughout the spleen and liver. Both were massively enlarged, and combined with a lower FDG uptake in the bone marrow of the central skeleton, being a reflection of the patient's MF [42]. Patients with MDS also show diffuse bone marrow FDG uptake. This has also been found in patients who had undergone FDG PET for other reasons. So, these reports demonstrate that diffuse FDG uptake by the bone marrow probably suggests neoplastic disease of the haematopoietic tissue [43]. FDG PET has been shown to be effective for the detection of bone marrow metastases from several malignancies including lung carcinoma, breast carcinoma, and lymphoma [44-48]. It is unclear to what extent lesions are involved in bone marrow and bone metastases.

A recent study in 21 patients with diffuse large B-cell lymphoma and bone marrow involvement showed that the bone marrow uptake of FDG depends on the histological 
type of cell infiltrate. In this study, FDG PET showed abnormal foci of uptake in most patients with concordant bone marrow involvement (prominent diffuse large B-cell lymphoma), whereas FDG uptake was normal in most patients with discordant bone marrow involvement (prominent indolent lymphoma) [49]. Another study demonstrated at initial staging of Hodgkin lymphoma that diffuse bone marrow uptake without splenic involvement may be due to Hodgkin lymphoma-related bone marrow involvement. However, these observations are more likely to be due to bone marrow inflammatory changes. In contrast, diffuse spleen uptake in combination with bone marrow uptake is probably more associated with disease involvement than with inflammatory changes [50]. Moreover, in a study of the role of FDG as a tracer to visualize bone marrow metastases in 257 patients with newly diagnosed lung cancer, the accuracy, sensitivity and specificity of FDGPET and bone scintigraphy were found to be $94 \%$ vs $85 \%$, $91 \%$ vs $75 \%$, and $96 \%$ vs $95 \%$, respectively [44].

A previous study investigating the bone marrow status in 112 breast cancer patients with N0 or N1 disease (who had undergone bone marrow aspiration twice) demonstrated that tumour cells were present in the bone marrow in $83 \%$ of the patients at the time of primary surgery. This was reduced to $24 \% 12$ months after initiation of adjuvant systemic chemotherapy [51]. This supports the concept that systemic treatment is effective in reducing the number of tumour cells within the bone marrow. Further studies are warranted to investigate this differential response to systemic therapy. When metastases are mainly confined to the bone marrow compared to those that involve the bone matrix, this would further enhance the role of metabolic imaging of bone marrow metastases by FDG PET in various malignant disorders.

FDG PET can also be used for the evaluation of CML or acute lymphoblastic leukaemia (ALL) [52, 53]. Follow-up FDG PET scans were performed in patients with CML after termination of treatment [53]. FDG PET findings showed reduced FDG uptake in the bone marrow. Also localized relapse of ALL in bone marrow can be visualized with FDG PET [52]. FDG PET has already been shown to be useful in the initial staging of multiple myeloma patients (Fig. 2). It has also been demonstrated to be valuable in patients with solitary plasmacytoma in bone as well as in patients suffering from extramedullary plasmacytoma [54]. Somatostatin receptor scintigraphy using ${ }^{111}$ In-pentetreotide may also be a good alternative to find the malignant plasma cells in multiple myeloma and plasmacytoma patients, especially at relapse [55]. ${ }^{99 \mathrm{~m}} \mathrm{Tc}$-sestamibi has also been proposed as a potential tracer in patients with multiple myeloma [56]. The patterns of ${ }^{99 \mathrm{~m}} \mathrm{Tc}$-sestamibi uptake in patients with multiple myeloma are related to both the clinical status and the stage of disease. The presence of
Fig. 2 FDG PET image in a patient with multiple myeloma. Lesions are visible in the ribs, right scapula and sternum

focal uptake or of intense diffuse bone marrow uptake suggests that the patient has active and advanced stage disease, while a negative scan in a patient with multiple myeloma clearly indicates remission [56]. Compared with ${ }^{99} \mathrm{~m}$ Tc-sestamibi FDG PET/CT performs better in the detection of focal lesions, whereas ${ }^{99 \mathrm{~m}} \mathrm{Tc}$-sestamibi is superior in the visualization of diffuse disease in the spine and pelvis [57]. Finally, it is considered that FDG PET may become useful in the initial staging, follow-up, and restaging of patients with bone marrow malignancy.

Imaging the proliferative activity

The thymidine analogue 3 -deoxy-3- ${ }^{18} \mathrm{~F}$-fluorothymidine $\left({ }^{18} \mathrm{~F}\right.$-FLT) was developed as a PET tracer to image cell proliferation [58]. The pyrimidine analogue thymidine is incorporated into DNA and undergoes the same first metabolic step as thymidine. ${ }^{18}$ F-FLT is taken up by the cell by both passive diffusion and facilitated transport by $\mathrm{Na}^{+}$-dependent carriers. Subsequently, ${ }^{18}$ F-FLT is phosphorylated by thymidine kinase 1 (TK1) into ${ }^{18} \mathrm{~F}$-FLT monophosphate, after which it is trapped in the cell. The phosphorylation by TK1 forms the basis of ${ }^{18} \mathrm{~F}$-FLT as a proliferation tracer. As a result of this behaviour, reduced ${ }^{18} \mathrm{~F}$-FLT uptake is seen in the affected area after radiother- 


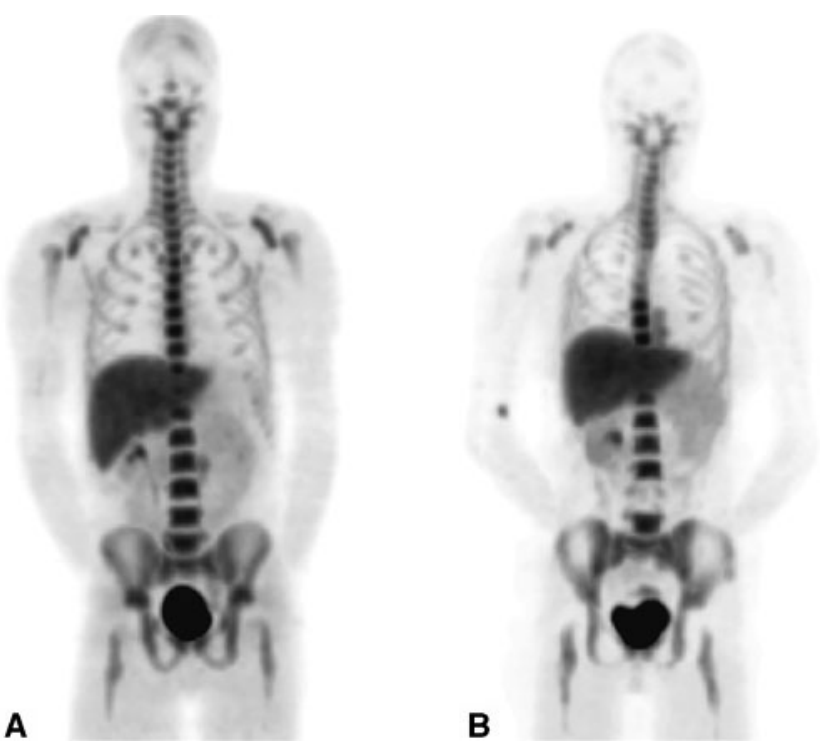

Fig. 3 a Normal distribution of ${ }^{18}$ F-FLT PET. b The effect of radiotherapy on bone marrow activity in (a) the fourth lumbar vertebra and (b) the midthoracic vertebrae

apy (Fig. 3). Accordingly, increased ${ }^{18}$ F-FLT uptake in bone marrow and spleen is seen in patients with acute myeloid leukaemia. This uptake is significantly higher in patients with relapsed, refractory, or untreated leukaemia [59]. Therefore, ${ }^{18}$ F-FLT could be an imaging biomarker of disease activity. EMH lesions can also be seen with ${ }^{18} \mathrm{~F}$ FLT PET (Fig. 4e).

In a recent pilot study, we demonstrated ${ }^{18} \mathrm{~F}$-FLT distribution in haematological disorders [60]. There is increased ${ }^{18} \mathrm{~F}$-FLT uptake in the bone marrow areas compared with that in healthy control subjects and a significant expansion of the bone marrow compartment in patients with MDS (Fig. 4b). Patients with MPD showed remarkable expansion of the bone marrow with high uptake (see Fig. 4c). Despite the large size of the liver and spleen in two patients with MPD, ${ }^{18} \mathrm{~F}$-FLT uptake in these organs was not elevated. Significantly higher uptake in the spleen and liver with distinct hepatosplenomegaly was characteristic of MF, with bone marrow uptake significantly reduced and expansion may be seen (Fig. 4d). ${ }^{18}$ F-FLT may also be a valuable tool for visualizing the bone marrow compartment and is able to identify solitary areas of increased proliferative activity that can frequently be recognized in patients with AA (Fig. 4a). Increased ${ }^{18}$ F-FLT uptake was demonstrated after stem cell transplantation in a group of patients with lymphoma. At the same time there was an extension of bone marrow activity in the peripheral skeleton. These findings correlated with in vitro data showing a higher proliferative activity of haematopoietic progenitor cells [61]. ${ }^{18} \mathrm{~F}$-FLT PET may be a promising method for noninvasive evaluation of bone marrow activity after bone marrow transplantation.

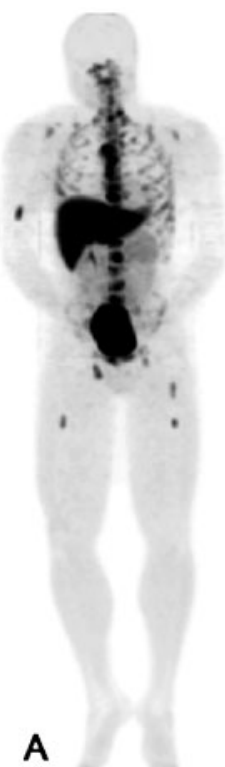

Fig. 4 Different bone marrow patterns in ${ }^{18}$ F-FLT PET. a A patient with AA. Several patchy hot lesions with increased proliferative activity are visible in the spine and femora, and mainly higher liver uptake compared to controls. b A patient with MDS shows a relatively homogeneous ${ }^{18} \mathrm{~F}$-FLT PET pattern in the bone marrow of the spine and relative heterogeneous expansion in the extremities, but the extremities can also be homogeneous. There is normal uptake in the
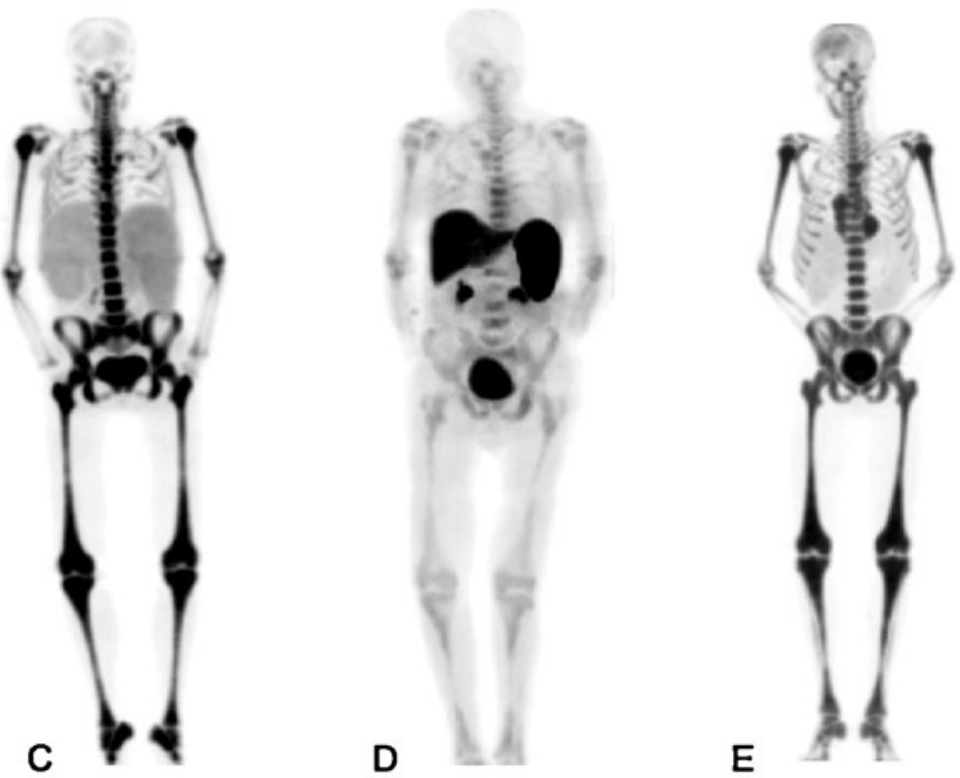

liver and spleen. c A patient with MPD shows homogeneously increased uptake and extensive peripheral bone marrow expansion into extremity bones and no elevated uptake in the liver or (enlarged) spleen. d A patient with MF shows low uptake in the bone marrow compartment. Elevated uptake in the enlarged spleen and moderate elevated uptake in the liver as a result of extramedullary haematopoiesis. e A patient with thoracic paravertebral EMH with $\beta$-thalassaemia 
${ }^{11} \mathrm{C}$-Methionine is another PET compound that can be used for imaging the amino acid activity in highly proliferative tissues, such as bone marrow [62]. The mechanism of increased uptake of ${ }^{11} \mathrm{C}$-methionine in bone marrow has been described as an expression of increased cellular proliferation and protein synthesis [63]. Multiple myeloma is a process characterized by neoplastic proliferation of plasma cells, and these cells nearly always produce complete monoclonal immunoglobulins or monoclonal immunoglobulin light chains. The unrestricted expansion of a plasma cell clone and the excessive synthesis of monoclonal immunoglobulins result in extensive skeletal destruction and anaemia. ${ }^{11} \mathrm{C}$-Methionine incorporation into immunoglobulins of the malignant plasma cell clone in vivo can be assumed. On the basis of increased methionine uptake in plasma cells, active multiple myeloma can be imaged with ${ }^{11} \mathrm{C}$-methionine PET [63]. Nunez et al. compared ${ }^{11} \mathrm{C}$-methionine with FDG PET in 12 patients with metastatic prostate cancer. ${ }^{11} \mathrm{C}$-Methionine PET was more effective than FDG PET for detecting bone metastases, including bone marrow involvement in this patient population [62].

The potential advantages of PET using radiolabelled phospholipids, such as ${ }^{11} \mathrm{C}$ - and ${ }^{18} \mathrm{~F}$-labelled choline, in the assessment of patients with prostate cancer have been emphasized in previous studies [64, 65]. Choline uptake seems to be a marker of cell proliferation in prostate cancer, as malignancies are commonly characterized by increased proliferative activity. The second explanation proposed is upregulation of choline kinase in cancer cells: overexpression of choline kinase has been found in cancer cell lines, including human-derived prostate cancer [66]. Cimitan et al. examined 100 postoperative prostate cancer patients with persistently increased serum PSA levels, suggestive of local recurrences or distant metastases. ${ }^{18} \mathrm{~F}$-Choline PET/ CT correctly detected bone involvement in $21 \%$ of patients; also $76 \%$ of them were undergoing hormone therapy [64]. Bone marrow metastases were not scored separately in this study, but ${ }^{18} \mathrm{~F}$-choline may be an interesting PET tracer for this purpose.

${ }^{11} \mathrm{C}$-Acetate has also recently been used for the imaging of prostate cancer and the genitourinary system and is suitable for visualizing the pelvis due to its lack of urinary excretion and its acceptable tumour to background contrast $[67,68]$. Previously published data on the value of ${ }^{11} \mathrm{C}$ acetate PET show that it might have significant potential for the detection of recurrences and bone metastases when using more advanced PET/CT equipment [69]. Probably ${ }^{11} \mathrm{C}$-acetate may also be an interesting PET tracer for evaluation of bone marrow metastases. Recently, ${ }^{18} \mathrm{~F}$ fluoroacetate has been introduced as a possible alternative to ${ }^{11} \mathrm{C}$-acetate for PET imaging, especially with respect to its longer half-life [70].

\section{Future perspectives and conclusion}

Several patterns of bone marrow uptake can be identified depending on the haematopoietic activity, the underlying disorder and the radiopharmaceutical used. Bone marrow activity can be more or less identically recognized with gamma and PET cameras. However, differences have been noted in the resolution and quality, and PET offers the ability to quantify standardized uptake values of the bone marrow activity. Different targets can be used for imaging the total normal and diseased bone marrow compartment. This is an advantage compared to a bone marrow biopsy by which $1-2 \mathrm{~cm}$ of the bone marrow compartment is evaluated. Imaging may help to differentiate various bone marrow diseases and may play a part in monitoring treatment and bone marrow transplantation. There are new developments in PET tracers for the field of nuclear medicine. Imaging of hypoxia and programmed cell death in the bone marrow compartment are two features that may be used in the future for monitoring disease activity or for studying the effects of therapy including chemotherapy, kinase inhibitors or radiotherapy [71].

A number of agents exploit the low oxygen tension in hypoxic tissues to permit intercellular trapping by reductive mechanisms. $\left[{ }^{18} \mathrm{~F}\right]$ Fluoromisonidazole-3-fluoro-1-(2'-nitro1'-imidazolyl)-2-propanol $\left({ }^{18} \mathrm{~F}\right.$-MISO) and ${ }^{64} \mathrm{Cu}$-diacetylbis $\left(N^{4}\right.$-methylthiosemicarbazone $\left({ }^{64} \mathrm{Cu}\right.$-ATSM $)$, and the recently introduced $\left[{ }^{18} \mathrm{~F}\right]$ fluoroazomycinarabinoside $\left({ }^{18} \mathrm{~F}\right.$ FAZA) are the lead contenders for human application. Their promise is based on their noninvasive nature, ease of use and robustness, ability to measure hypoxia status, validity, ability to demonstrate heterogeneity, and general availability $[71,72] .{ }^{18} \mathrm{~F}$-FAZA uptake by normal bone marrow cells is relative low, but may potentially increase under hypoxic conditions [71]. Visualization of apoptosis or programmed cell death with ${ }^{18} \mathrm{~F}$-annexin A5 may be of use to study the effectiveness of treatment in leukaemia, myeloma or MPDs [73].

In future, ${ }^{18} \mathrm{~F}$-immuno-PET or labelling with the PET label ${ }^{89} \mathrm{Zr}$ with a longer life is of interest for the determination of CD66 distribution in the bone marrow, especially for the evaluation of leukaemia [74]. The CD66 antigen is expressed at the cell surface of mature myeloid cells including promyelocytes and granulocytes. It is therefore an attractive target for the detection of the extent of the monotonous population of leukaemic cells in the bone marrow and probably also of value for the monitoring of minimal residual disease following treatment. AntiCD66 monoclonal antibodies labelled with beta-emitting nuclides $\left({ }^{188} \mathrm{Re}\right.$ and $\left.{ }^{90} \mathrm{Y}\right)$ have already been introduced and can be used as part of the treatment for high-risk leukaemia [75]. Neovascularization is also a prominent feature of malignant transformation. Recently different agents have 
been introduced into clinical practice, including monoclonal antibodies against VEGF or kinase inhibitors of the VEGF receptor. New imaging tools with ${ }^{89} \mathrm{Zr}$-bevacizumab have become available in solid tumours for visualization of neovascularization [76]. This might also be an attractive approach for haematological disorders since enhanced neovascularization is also a prominent feature in acute myeloid leukaemia [77].

In conclusion, a variety of bone marrow targets can be imaged with radionuclide imaging, where PET offers the possibility of absolute quantification of bone marrow activity. Imaging may help differentiate various bone marrow diseases and may play a role in monitoring treatment effects.

Acknowledgment We thank Jan Pruim, Douwe Buiter and Albertus Piers for technical assistance.

\section{Conflicts of interest None.}

Open Access This article is distributed under the terms of the Creative Commons Attribution Noncommercial License which permits any noncommercial use, distribution, and reproduction in any medium, provided the original author(s) and source are credited.

\section{References}

1. Rubin R, Strayer DS. Rubin's pathology: clinicopathologic foundations of medicine. Philadelphia: Lippincott Williams \& Wilkins; 2007.

2. Rizo A, Vellenga E, de Haan G, Schuringa JJ. Signaling pathways in self-renewing hematopoietic and leukemic stem cells: do all stem cells need a niche? Hum Mol Genet 2006;15(Spec no 2): R210-9

3. Johnsen HE, Kjeldsen MK, Urup T, Fogd K, Pilgaard L, Boegsted $M$, et al. Cancer stem cells and the cellular hierarchy in haematological malignancies. Eur J Cancer 2009;45 Suppl 1:194-201.

4. Vardimann JW. Myelodysplastic/myeloproliferative diseases. In: Finn WG, Peterson LC, editors. Hematopathology in oncology. New York: Springer US; 2004. p. 13-43.

5. Schepers H, van Gosliga D, Wierenga AT, Eggen BJ, Schuringa JJ, Vellenga E. STAT5 is required for long-term maintenance of normal and leukemic human stem/progenitor cells. Blood 2007;110:2880-8.

6. Koch CA, Li CY, Mesa RA, Tefferi A. Nonhepatosplenic extramedullary hematopoiesis: associated diseases, pathology, clinical course, and treatment. Mayo Clin Proc 2003;78:1223-33.

7. Charache S, Page DL. Infarction of bone marrow in the sickle cell disorders. Ann Intern Med 1967;67:1195-200.

8. Lutzker LG, Alavi A. Bone and marrow imaging in sickle cell disease: diagnosis of infarction. Semin Nucl Med 1976;6:83-93.

9. Swerdlow SH, Campo E, Harris NL, Jaffe ES, Pileri SA, Stein H, et al. World Health Organization (WHO) classification of tumors of hematopoietic and lymphoid tissues. 4th ed. Lyon: IARC Press; 2009.

10. Delhommeau F, Dupont S, Della Valle V, James C, Trannoy S, Masse A, et al. Mutation in TET2 in myeloid cancers. N Engl J Med 2009;360:2289-301.
11. Jaffe ES, Harris NL, Stein H, Vardiman JW. Tumours of haematopoietic and lymphoid tissue, pathology and genetics. World Health Organization classification of tumours. Lyon: IARC Press, 2001.

12. Tefferi A, Spivak JL. Polycythemia vera: scientific advances and current practice. Semin Hematol 2005;42:206-20.

13. Tennvall J, Brans B. EANM procedure guideline for $32 \mathrm{P}$ phosphate treatment of myeloproliferative diseases. Eur J Nucl Med Mol Imaging 2007;34:1324-7.

14. Tam CS, Kantarjian H, Cortes J, Lynn A, Pierce S, Zhou L, et al. Dynamic model for predicting death within 12 months in patients with primary or post-polycythemia vera/essential thrombocythemia myelofibrosis. J Clin Oncol 2009;27:5587-93.

15. Greenberg P, Anderson J, de Witte T, Estey E, Fenaux P, Gupta P, et al. Problematic WHO reclassification of myelodysplastic syndromes Members of the International MDS Study Group. J Clin Oncol 2000;18:3447-52.

16. Williamson PJ, Kruger AR, Reynolds PJ, Hamblin TJ, Oscier DG. Establishing the incidence of myelodysplastic syndrome. Br J Haematol 1994;87:743-5.

17. Young NS. Acquired aplastic anemia. Ann Intern Med 2002;136:534-46.

18. Young NS, Scheinberg P, Calado RT. Aplastic anemia. Curr Opin Hematol 2008;15:162-8.

19. Pitcher LA, Hann IM, Evans JP, Veys P, Chessells JM, Webb DK. Improved prognosis for acquired aplastic anaemia. Arch Dis Child 1999;80:158-62.

20. Desai AG, Thakur ML. Radiopharmaceuticals for spleen and bone marrow studies. Semin Nucl Med 1985;15:229-38.

21. Reske SN. Recent advances in bone marrow scanning. Eur J Nucl Med 1991;18:203-21.

22. Milner PF, Brown M. Bone marrow infarction in sickle cell anemia: correlation with hematologic profiles. Blood 1982;60:1411-9.

23. Blebea JS, Houseni M, Torigian DA, Fan C, Mavi A, Zhuge Y, et al. Structural and functional imaging of normal bone marrow and evaluation of its age-related changes. Semin Nucl Med 2007;37:185-94.

24. Ferrant A, Rodhain J, Leners N, Cogneau M, Verwilghen RL, Michaux JL, et al. Quantitative assessment of erythropoiesis in bone marrow expansion areas using $52 \mathrm{Fe}$. $\mathrm{Br} \mathrm{J}$ Haematol 1986;62:247-55.

25. Datz FL, Taylor A Jr. The clinical use of radionuclide bone marrow imaging. Semin Nucl Med 1985;15:239-59.

26. Itoh $\mathrm{H}$, Kanamori $\mathrm{M}$, Takahashi N. Dissociation between In-111 chloride and Tc-99m colloid bone marrow scintigraphy in refractory anemia with excess blasts. Clin Nucl Med 1990;15:124-5.

27. Sayle BA, Helmer III RE, Birdsong BA, Balachandran S, Gardner $\mathrm{FH}$. Bone-marrow imaging with indium-111 chloride in aplastic anemia and myelofibrosis: concise communication. J Nucl Med 1982;23:121-5.

28. Rain JD, Najean Y. Bone marrow scintigraphy in myelofibrosis. Nouv Rev Fr Hematol 1993;35:101-2.

29. McNeil BJ, Rappeport JM, Nathan DG. Indium chloride scintigraphy: an index of severity in patients with aplastic anaemia. Br J Haematol 1976;34:599-604.

30. Hotta T, Murate T, Inoue C, Kagami T, Tsushita K, Wang JY, et al. Patchy haemopoiesis in long-term remission of idiopathic aplastic anaemia. Eur J Haematol 1990;45:73-7.

31. Huic D, Ivancevic V, Richter WS, Munz DL. Immunoscintigraphy of the bone marrow: normal uptake values of technetium-99mlabeled monoclonal antigranulocyte antibodies. J Nucl Med 1997;38:1755-8.

32. Wahren B, Gahrton G, Hammarstrom S. Nonspecific crossreacting antigen in normal and leukemic myeloid cells and serum of leukemic patients. Cancer Res 1980;40:2039-44. 
33. Becker W, Borst U, Fischbach W, Pasurka B, Schafer R, Borner W. Kinetic data of in-vivo labeled granulocytes in humans with a murine Tc-99m-labelled monoclonal antibody. Eur J Nucl Med 1989;15:361-6.

34. Reske SN, Karstens JH, Gloeckner W, Steinstrasser A, Schwarz A, Ammon J, et al. Radioimmunoimaging for diagnosis of bone marrow involvement in breast cancer and malignant lymphoma. Lancet 1989;1:299-301.

35. Munz DL, Voth E, Emrich D. Different approaches to determine the uptake ratio of bone-marrow-seeking radiopharmaceuticals for classifying the scintigraphic bone marrow status. Nuc Compact 1987;18:192-4.

36. Bonner H. Pathology. Philadelphia: Lippincott; 2009.

37. Inoue $\mathrm{K}$, Goto R, Okada K, Kinomura S, Fukuda H. A bone marrow F-18 FDG uptake exceeding the liver uptake may indicate bone marrow hyperactivity. Ann Nucl Med 2009;23:643-9.

38. Sugawara Y, Fisher SJ, Zasadny KR, Kison PV, Baker LH, Wahl RL. Preclinical and clinical studies of bone marrow uptake of fluorine-1-fluorodeoxyglucose with or without granulocyte colony-stimulating factor during chemotherapy. J Clin Oncol 1998;16:173-80.

39. Knopp MV, Bischoff H, Rimac A, Oberdorfer F, van Kaick G. Bone marrow uptake of fluorine-18-fluorodeoxyglucose following treatment with hematopoietic growth factors: initial evaluation. Nucl Med Biol 1996;23:845-9.

40. Basu S, Asopa R, Peshwe H, Mohandas KM. Diffuse intense FDG uptake in the bone marrow in gastrointestinal stromal tumor with coexistent polycythemia rubra vera. Clin Nucl Med 2008;33:782-3.

41. Quarles van Ufford HM, de Jong JA, Baarslag HJ, de Haas MJ, Oud K, de Klerk JM. FDG PET in a patient with polycythemia vera. Clin Nucl Med 2008;33:780-781

42. Burrell SC, Fischman AJ. Myelofibrosis on F-18 FDG PET Imaging. Clin Nucl Med 2005;30:674.

43. Inoue K, Okada K, Harigae H, Taki Y, Goto R, Kinomura S, et al. Diffuse bone marrow uptake on F-18 FDG PET in patients with myelodysplastic syndromes. Clin Nucl Med 2006;31:721-3.

44. Cheran SK, Herndon JE, Patz EF Jr. Comparison of whole-body FDG-PET to bone scan for detection of bone metastases in patients with a new diagnosis of lung cancer. Lung Cancer 2004;44:317-25.

45. Kumar R, Alavi A. Fluorodeoxyglucose-PET in the management of breast cancer. Radiol Clin N Am 2004;42:1113-22.

46. Kumar R, Maillard I, Schuster SJ, Alavi A. Utility of fluorodeoxyglucose-PET imaging in the management of patients with Hodgkin's and non-Hodgkin's lymphomas. Radiol Clin N Am 2004;42:1083-100.

47. Mavi A, Lakhani P, Zhuang H, Gupta NC, Alavi A. Fluorodeoxyglucose-PET in characterizing solitary pulmonary nodules, assessing pleural diseases, and the initial staging, restaging, therapy planning, and monitoring response of lung cancer. Radiol Clin N Am 2005;43:1-21.

48. Moog F, Bangerter M, Kotzerke J, Guhlmann A, Frickhofen N, Reske SN. 18-F-fluorodeoxyglucose-positron emission tomography as a new approach to detect lymphomatous bone marrow. J Clin Oncol 1998;16:603-9.

49. Paone G, Itti E, Haioun C, Gaulard P, Dupuis J, Lin C, et al. Bone marrow involvement in diffuse large B-cell lymphoma: correlation between FDG-PET uptake and type of cellular infiltrate. Eur J Nucl Med Mol Imaging 2009;36:745-50.

50. Salaun PY, Gastinne T, Bodet-Milin C, Campion L, Cambefort P, Moreau A, et al. Analysis of 18F-FDG PET diffuse bone marrow uptake and splenic uptake in staging of Hodgkin's lymphoma: a reflection of disease infiltration or just inflammation? Eur J Nucl Med Mol Imaging 2009;36:1813-21.

51. Becker S, Becker-Pergola G, Wallwiener D, Solomayer EF, Fehm T. Detection of cytokeratin-positive cells in the bone marrow of breast cancer patients undergoing adjuvant therapy. Breast Cancer Res Treat 2006;97:91-6.

52. Endo T, Sato N, Koizumi K, Nishio M, Fujimoto K, Sakai T, et al. Localized relapse in bone marrow of extremities after allogeneic stem cell transplantation for acute lymphoblastic leukemia. Am J Hematol 2004;76:279-82.

53. Nakajo M, Jinnouchi S, Inoue H, Otsuka M, Matsumoto T, Kukita $\mathrm{T}$, et al. FDG PET findings of chronic myeloid leukemia in the chronic phase before and after treatment. Clin Nucl Med 2007;32:775-8.

54. Jadvar H, Conti PS. Diagnostic utility of FDG PET in multiple myeloma. Skeletal Radiol 2002;31:690-4.

55. Agool A, Slart RH, Dierckx RA, Kluin PM, Visser L, Jager PL, et al. Somatostatin receptor scintigraphy might be useful for detecting skeleton abnormalities in patients with multiple myeloma and plasmacytoma. Eur J Nucl Med Mol Imaging 2010;37:124-30.

56. Pace L, Catalano L, Pinto A, De Renzo A, Di Gennaro F, Califano C, et al. Different patterns of technetium-99m sestamibi uptake in multiple myeloma. Eur J Nucl Med 1998;25:714-20.

57. Fonti R, Salvatore B, Quarantelli M, Sirignano C, Segreto S, Petruzziello F, et al. 18F-FDG PET/CT, 99mTc-MIBI, and MRI in evaluation of patients with multiple myeloma. J Nucl Med 2008;49:195-200.

58. Shields AF, Grierson JR, Dohmen BM, Machulla HJ, Stayanoff JC, Lawhorn-Crews JM, et al. Imaging proliferation in vivo with [F-18]FLT and positron emission tomography. Nat Med 1998;4:1334-6.

59. Buck AK, Bommer M, Juweid ME, Glatting G, Stilgenbauer S, Mottaghy FM, et al. First demonstration of leukemia imaging with the proliferation marker $18 \mathrm{~F}$-fluorodeoxythymidine. J Nucl Med 2008;49:1756-62.

60. Agool A, Schot BW, Jager PL, Vellenga E. 18F-FLT PET in hematologic disorders: a novel technique to analyze the bone marrow compartment. J Nucl Med 2006;47:1592-8.

61. Woolthuis C, Agool A, Olthof S, Slart RH, Huls G, Smid WM, et al. Auto-SCT induces a phenotypic shift from CMP to GMP progenitors, reduces clonogenic potential and enhances in vitro and in vivo cycling activity defined by (18)F-FLT PET scanning. Bone Marrow Transplant 2010. DOI: 10.1038/bmt.2010.75

62. Nunez R, Macapinlac HA, Yeung HW, Akhurst T, Cai S, Osman $\mathrm{I}$, et al. Combined 18F-FDG and 11C-methionine PET scans in patients with newly progressive metastatic prostate cancer. J Nucl Med 2002;43:46-55

63. Dankerl A, Liebisch P, Glatting G, Friesen C, Blumstein NM, Kocot D, et al. Multiple myeloma: molecular imaging with 11C-methionine PET/CT - initial experience. Radiology 2007;242: 498-508.

64. Cimitan M, Bortolus R, Morassut S, Canzonieri V, Garbeglio A, Baresic T, et al. [18F]Fluorocholine PET/CT imaging for the detection of recurrent prostate cancer at PSA relapse: experience in 100 consecutive patients. Eur $\mathrm{J}$ Nucl Med Mol Imaging 2006;33:1387-98.

65. Kwee SA, Thibault GP, Stack RS, Coel MN, Furusato B, Sesterhenn IA. Use of step-section histopathology to evaluate 18F-fluorocholine PET sextant localization of prostate cancer. Mol Imaging 2008;7:12-20.

66. Zheng QH, Gardner TA, Raikwar S, Kao C, Stone KL, Martinez TD, et al. [11C]Choline as a PET biomarker for assessment of prostate cancer tumor models. Bioorg Med Chem 2004; 12:2887-93.

67. de Jong IJ, Pruim J, Elsinga PH, Vaalburg W, Mensink HJ. Visualization of prostate cancer with $11 \mathrm{C}$-choline positron emission tomography. Eur Urol 2002;42:18-23.

68. Shreve P, Chiao PC, Humes HD, Schwaiger M, Gross MD. Carbon-11-acetate PET imaging in renal disease. J Nucl Med 1995;36:1595-601. 
69. Albrecht S, Buchegger F, Soloviev D, Zaidi H, Vees H, Khan HG, et al. (11)C-Acetate PET in the early evaluation of prostate cancer recurrence. Eur J Nucl Med Mol Imaging 2007;34:185-96.

70. Ponde DE, Dence CS, Oyama N, Kim J, Tai YC, Laforest R, et al. 18F-Fluoroacetate: a potential acetate analog for prostate tumor imaging - in vivo evaluation of $18 \mathrm{~F}$-fluoroacetate versus $11 \mathrm{C}$ acetate. J Nucl Med 2007;48:420-8.

71. Souvatzoglou M, Grosu AL, Roper B, Krause BJ, Beck R, Reischl G, et al. Tumour hypoxia imaging with [18F]FAZA PET in head and neck cancer patients: a pilot study. Eur J Nucl Med Mol Imaging 2007;34:1566-75.

72. Padhani A. PET imaging of tumour hypoxia. Cancer Imaging 2006;6:S117-21.

73. Baumann P, Mandl-Weber S, Volkl A, Adam C, Bumeder I, Oduncu F, et al. Dihydroorotate dehydrogenase inhibitor A771726 (leflunomide) induces apoptosis and diminishes proliferation of multiple myeloma cells. Mol Cancer Ther 2009;8:366-75.
74. Neumaier B, Mottaghy FM, Buck AK, Glatting G, Blumstein NM, Mahren B, et al. (18)F-Immuno-PET: Determination of antiCD66 biodistribution in a patient with high-risk leukemia. Cancer Biother Radiopharm 2008;23:819-24

75. Ringhoffer $M$, Blumstein $N$, Neumaier B, Glatting $G$, von Harsdorf S, Buchmann I, et al. 188Re or 90Y-labelled anti-CD66 antibody as part of a dose-reduced conditioning regimen for patients with acute leukaemia or myelodysplastic syndrome over the age of 55: results of a phase I-II study. Br J Haematol 2005;130:604-13.

76. Nagengast WB, de Vries EG, Hospers GA, Mulder NH, de Jong JR, Hollema $H$, et al. In vivo VEGF imaging with radiolabeled bevacizumab in a human ovarian tumor xenograft. J Nucl Med 2007;48:1313-9.

77. de Bont ES, Rosati S, Jacobs S, Kamps WA, Vellenga E. Increased bone marrow vascularization in patients with acute myeloid leukaemia: a possible role for vascular endothelial growth factor. Br J Haematol 2001;113:296-304. 